Article

\title{
Living and Dealing with Food in an Affluent Society-A Case for the Study of Lived (Non)Religion
}

\author{
Anna Sofia Salonen (D) \\ Faculty of Social Sciences, University of Tampere, FI-33014 Tampere, Finland; anna.salonen@uta.fi
}

Received: 2 August 2018; Accepted: 6 October 2018; Published: 10 October 2018

check for updates

\begin{abstract}
Significant changes have been taking place in the field of the sociology of religion in the last few decades, which challenge researchers to rethink this scholarly field. This article suggests that a great deal could be learned about the current dilemmas within this field through research that explores the moral underpinnings of everyday food consumption within contemporary society that is characterized by abundance. More specifically, the article proposes that everyday food consumption and everyday ethics provide unique opportunities to transcend and surpass crucial distinctions within social sciences in a way that can feed the sociological imagination in relation to research on lived (non)religion. Drawing on examples from research on food consumption in the nonreligious context and at the individual, discursive and institutional levels, this study shows how the everyday ethics of food consumption can serve as a point of departure for sociological research, which could help researchers to understand the currents of lived religion and nonreligion in a way that evades the idea of religion as a certain set of practices or beliefs, or as a specific religious affiliation. This research would enable the study of issues such as practices, beliefs, meanings and belonging, as well as distancing, withdrawal, and indifference.
\end{abstract}

Keywords: lived religion; nonreligion; food; consumption; affluence

\section{Introduction}

Today's Western societies can be regarded as affluent societies that provide people with opportunities beyond basic necessities. These opportunities for individual self-realization are largely related to and facilitated by consumption. Modern affluent societies have been brought about by material and ideological changes, by industrialization and advances in the means of production, and by the ideas of enlightenment, which attempted to make material goods, at least in principle, legitimate for everyone and not only for the privileged few. However, affluence has not straightforwardly led to material wealth for all. It has not eliminated social problems; it has altered the context in which they emerge and has created new challenges (Lorenz 2015, pp. 2-4).

Contemporary society marks a historically exceptional situation in which a considerable number of people live in profusion rather than paucity, and in which the central everyday question is not how to make ends meet but rather: How much is enough? This is demonstrated in many current commercial and communal trends that call attention to clearing, organising and living with material belongings. However, even though we are faced with abundance and excess, social theory has taken scarcity as its self-evident point of departure (e.g., Abbott 2014).

The abundance of everyday life manifests particularly in food and eating. Excessive food consumption and wastage of food have been traditionally considered reprehensible, or even a sin. However, food excess also has a positive side; it enables virtuous acts, such as care, hospitality, communality, and charity (cf. Salonen 2016; Evans 2012; Miller 1997). Food consumption enables us to both care for and mistreat ourselves, others, the environment, and society. In everyday food 
consumption, we constantly face the question of how to lead an ethically sound life in the midst of a culture that is characterized by excess and waste.

Meanwhile, in recent decades, significant changes have been taking place in the field of the sociology of religion. As the traditional approaches within the discipline cannot cope with the state of affairs of religion in the contemporary world, it has been suggested that we ought to expand this field by looking, for example, at our research object from alternative perspectives (e.g., Spickard 2017) and focusing on meaning systems other than religious ones (e.g., Dobbelaere 2014). It seems insufficient to study religion as a belief system, as an institutional affiliation, or as an individual's sense of the sacred or transcendent. In this article, I take these notions into account by distancing myself from the traditional approaches that primarily look at religion as a belief, and by engaging in thinking about this-worldly everyday practices that do not explicitly fall into the category of religion. In particular, I suggest that a great deal could be learned about the current dilemmas in the scholarly field of the sociology of religion through research that explores the moral underpinnings of everyday food consumption within contemporary society, which is characterized by abundance.

This article concentrates on post-Christian, Western consumer societies, where most of the food waste is produced on the household level, and were the implicit societal norms to which people still are invited to respond, descend historically from Christian theological heritage. Yet, I acknowledge that much could be learned by studying other contexts; for example, non-Christian cultural and religious traditions and the uneven distribution of food between the global North and South.

\section{Reaching Outside the Belief Box}

According to Vasquez (2013, p. 23), the issues currently facing the field of the sociology of religion are rooted in the history of sociology and modernity. Modernity has replaced faith and revelation by rationality and empirical observation. Social theorists' conceptual separation of society and religion led to the idea of religion as a contingent, rather than fundamental matter in human social life. Even though religion played a central role in the writings of early social theorists, such as, for example, Max Weber, Émile Durkheim, and Karl Marx, their works construed religion as a perishable phenomenon, and thus its presence needed explanation (Vasquez 2013; Beckford 1989). As a consequence of the concomitant rise of the secularization paradigm, religion was cleared from the public sphere to the domain of the inessential (Vasquez 2013, pp. 27-28), and it became defined as "individuals' beliefs about matters that don't matter politically" (Harvey 2014, p. 65).

The idea(l) of religion that resulted from modernity was, according to Vasquez (2013, pp. 30-32), one in which Christianity—-particularly in its Protestant form—-became the paradigm for modern religion. This paradigm primarily considers religion as a deeply held set of beliefs that orient and shape the behaviour of groups and individuals. Harvey $(2013$, pp. 41,54) states that the pivotal problem in the contemporary study of religion, which dates back to these early modern premises, is the "scholarly belief in belief", that is: the idea that religion is about believing. Both Harvey and Vasquez argue that overcoming this bias would enhance scholarly attempts to understand the rich reality of religion entwined in human life (Harvey 2013; Vasquez 2013, p. 38).

In their search for other ways to approach religion, many researchers have turned to mundane, everyday life. Harvey (2013) suggests that, instead of approaching religion as a belief in God or as a representation of ultimate concerns, it should be understood as an everyday matter: "Religion has everything to do with the relationships that constitute, form, and enliven people in everyday activities in this material world" (Harvey 2013, p. 2). According to this view, religion is about negotiated practices of embodiment, about materiality rather than transcendent ideas and ideals; about power, discipline, and relationality between people and between human and nonhuman animals (Harvey 2013, p. 71; cf. Beaman 2017b).

In recent decades, in the field of the sociology of religion, many similar efforts have been made to rethink the study of religion "outside the belief-box". In this regard, a particularly significant research tradition is "lived religion". The lived religion approach deals with the manifestations of religion in the 
everyday life and the lived experiences of individuals. Instead of placing religion in the realm of official religious doctrine, clear-cut religious affiliation or pre-formulated and postulated beliefs and formal religious practice, this approach focuses on rituals, identity, mundane practices, and fluid, variable experiences. The study of lived religion emerged as a response to the inability of the theories of rational choice and secularization to explain the manifold reality in which religious manifestations occur in the contemporary world (McGuire 2008; Ammerman 2014, 2016). In the past three decades, lived religion approaches have significantly influenced research. According to Ammerman (2016, p. 95), "by insisting that we begin with experiences among ordinary people in everyday life, our field has been magnificently transformed".

The shift in the research focus from beliefs and formal religious practices to everyday life has resulted in many suggestions of how and where one ought to study religion. For example, in her quest to revise the scholarly approaches to the study of religion, McGuire $(2008$, p. 4) suggests that, instead of studying affiliation or organizational participation, one should focus "first on individuals, the experiences they consider most important, and the concrete practices that make up their personal religious experience and expression". In a similar vein, Ammerman calls for an integrated definition of religion that would incorporate various sorts of spiritualties. Instead of oppositions and sharp divisions between the sacred and the profane, the notions should be seen on a continuum, or as different ways of looking at and interacting with the world (Ammerman 2014, pp. 290-91). Orsi (2005, p. 2), in turn, encourages " $t$ thinking of religion as relationships between heaven and earth with the specific shapes that relationships take in particular times and spaces" in research. All in all, the research on lived religion calls attention to individual experiences, practices, and actions, to intermingling rather than distinguishing between the sacred and the profane, and to relationships and relationality between beings.

In addition to lived religion, another significant thread in the recent academic discussions on religion has been the question of nonreligion. Recently, sociologists of religion have started to pay close attention to the fact that in many parts of North America and Europe, a growing population of people are identifying themselves as "nons" (Woodhead 2017; Beaman and Tomlins 2015). Empirically, the growth of nonreligion is evident in many survey results, which show that people are increasingly reporting that they follow no religion, as opposed to affiliating with any particular religious organization of tradition. According to Woodhead (2017), nonreligion is the new normal; a noteworthy option in expressing a (non)religious identity in many European and North American societies.

It is important to note, however, that nonreligious people do not constitute a unified group. The category of nonreligion comprises atheists, agnostics, and humanists, together with those who do not wish to define themselves at all in the line of traditional religious categories. It has been suggested that the most significant characteristic of nonreligion in today's societies might be indifference (Beaman 2017b, p. 16). Be that as it may, in Woodhead's (Woodhead 2017, p. 250) words, "[o]ne of the most striking findings of research on the nons in liberal democracies is just how indistinct they are from the wider populations in their home countries in many respects". She continues to argue that nonreligious people "tick the 'no religion' box on surveys as a way of clearing the ground for a unique identity and refusing to be classed with those who are willing to see themselves as examples of a category" (Woodhead 2017, p. 253). This characterization of nonreligion aligns with wider cultural tendencies that emphasize authenticity, reflexivity, and the individual self as the primary locus of authority in forming personal identity.

Despite the growing interest in nons and nonreligion as a phenomenon, there is still much to explore in terms of the diversity of nonreligion, particularly in the context of everyday life. According to Beaman (2017b, p. 10) specific challenges are provided by "those spaces of flexibility, indecision, life course, and relational interaction that defy categorization and measurement". Such spaces have in recent decades been meritoriously occupied by scholars of lived religion. However, the lived religion approach has been delimited to a search of expressions and forms of religion in everyday life, and, in a sense, has become defined by what it excludes (cf. Ammerman 2016). Thus, there is a need for research 
on lived (non)religion, that is, the everyday expressions and manifestations of nonreligion and the ways in which people or communities who do not necessarily or primarily identify as religious, see the world, and their own and others' place in it (cf. Beaman 2017b, p. 11).

\section{Everyday Ethics and Food Consumption in the Study of Religion}

If one agrees with the suggestion that there is indeed a need to study lived (non)religion, then the question inevitably arises as to how and where this should be done. This section presents two spheres of everyday life which, in my view, might prove instructive: everyday food consumption and everyday ethics. The selection of these two domains as potential targets of research is based on insights from previous research, but also on the notion that both of these spheres provide unique possibilities to transcend and outdo crucial distinctions within social sciences in a way that can feed the sociological imagination in relation to research on (non)religion.

First, focusing on ordinary ethical conduct can provide an arena for research that exceeds the clear-cut boundaries between religion and nonreligion. Previous research on lived religion and nonreligion suggests that these research fields are closely connected to leading an ethical life. According to Ammerman, for example, lived religion is about our everyday decisions on how to live. In her study of religion in the everyday life of ordinary Americans, almost all of the study participants agreed that real spirituality is about living a virtuous life (Ammerman 2014, pp. 3, 45). Beaman (2017b), in turn, discusses nonreligion in the light of "living well together". In her study of sea turtle rescue as a site of shared human experience that moves beyond specific religious or nonreligious beliefs and practices, she investigated lived nonreligion by asking what motivates people and how they understand their place in the world and in the environment in which they live. The study suggests that lived nonreligion concerns everyday ethics, particularly when contextualized to sites that involve actions toward bettering or repairing the world (Beaman 2017b). Together, research of lived religion and research of nonreligion enter a territory that has a pervasive ethical dimension. Importantly, however, it is not only pursuing good that falls into their purview. Religion, or nonreligion, is not always about doing good things or being nice; it also involves the possibility of harm and violence (Harvey 2014, 2015).

Taking ethics as the starting point for a study of lived (non)religion is also akin to the perspective of ongoing boundary work between academic disciplines. Recently, critical notions have been expressed about how empirical research has failed to pay attention to the moral and ethical dimensions of social life, and how sociology has broken away from the research of morality. There is a need for sociologists to (re)consider questions of ethics and practical philosophy (e.g., Sayer 2004; Honneth 2010; Hitlin and Vaisey 2013), and in the field of social sciences, sociologists of religion are especially well equipped for this task. As an example, in his effort to restore the moral dimension of sociology, Sayer (2004) starts by asking the reader to reflect on questions such as "What do you care most about?" and "How do you feel you should be treated by others?" These questions are at the heart of research traditions within the sociology of religion which emphasize the lived experiences of ordinary people. Scholars studying religion (may) occupy a niche of sociology in which questions of morality and practical philosophy are particularly relevant. Beaman describes this momentum in the sociology of religion elegantly, by recounting how studying sea turtle rescue provides "insight into an emerging way of engaging with and conceptualizing the world that sociologists of religion are uniquely positioned to describe, measure, and understand" (Beaman 2017b, p. 9).

Second, food consumption is an intriguing topic through which to study lived (non)religion, since food is such a prevalent topic in everyday discussions and practices. Food consumption consists of the practices through which people acquire, process, eat, and dispose of food; the meanings they give to these practices; and, the ways in which these practices construct meanings (cf. Dallam et al. 2014, p. xviii). It relates to multiple moral issues in ordinary life, including caring, identity, health, and aesthetics (Grauel 2016). Zeller (2014, 2015), for example, refers to certain 
foodways, such as veganism and locavorism as quasireligious, since they serve as individual and group identity markers and enable people to engage in discourses of meaning and community.

Eating is also an interesting arena for social research, since it surpasses the dichotomy between individualism on the one hand, and sociability and collective action on the other. As Simmel (Simmel 1997, p. 130) puts it, eating is an exceptional sphere of life in that it involves having to absolutely forego that which the other person eats. Actually, according to Simmel, it is only the Eucharist that enables participants to eat the same, mysterious, unbroken whole. At the same time, despite its banal individualism, eating is universal, as everybody must eat, and this fact creates a space for social interaction, community, aesthetics, and norms. The trivial fact that we all consume it enables food to have such tremendous social significance. In a similar vein, Wirzba (2013, p. 376) describes the dual significance of food by stating that, from the theological perspective, food "matters because eating is the most regular and intimate way in which we place ourselves in the world. It is the most fundamental way in which we connect our lives with others".

However, despite the pervasiveness of food and eating in everyday life, in the history of theological thinking, Christianity seems to have held an ambivalent view on food. The sinfulness of food is evident in the narrative of Adam and Eve and in the positioning of gluttony as the cardinal sin that stimulates others. On the other hand, in the Eucharist, food and wine become the body of Christ and are thus given the utmost role in Christian liturgical life (Grummet 2014). Nevertheless, outside these extremes, the role of food in Christian theology seems to be indistinct, even though eating has been religiously significant in many everyday practices and for several religious groups throughout the history. Grummet (2014) outlines three structural reasons why Christianity's stance toward food is ambivalent. First of all, the early Christian theological thinking that focused on the relationships between the body and food influenced later theological outlooks, and food-related practices became considered as either a sin (according to the anti-assimilationist view that deemed the functions that food sustained as sinful) or indifferent (based on thinking that religious virtue primarily concerned internal prayer and not physical life). According to Grummet (2014, p. 15), the view of the soul as detachable from the physical body still inspires attitudes that consider dietary matters as unimportant in Christian life. Second, even though eating and drinking are at the heart of Christian thinking in the form of the Eucharist, Grummet (2014, pp. 15-16) suggests that the understanding of the Eucharist as primarily representing liturgy led to diverting theological attention away from everyday acts of eating. Paradoxically, food and drink have gained significance in the Eucharist by becoming something else. Third, the differentiation of Christianity and food is related to the differentiation of Christianity from other religions, particularly from Judaism. This boundary-making by taking distance from food rules might still have an effect on the indecisive relationship of Christian culture with food and foodways. Thus, while the contemporary secularized Western societies no longer explicitly adhere to such theological notions, they nevertheless in their part form the historical backdrop against which also current ambivalences regarding religion and food can be understood.

Regardless of this ambivalent legacy of theology, food and eating share strong connections with religion, and this is also true to some extent in today's Western, secularized world. Previous literature on lived religion shows that in many ways, food practices incorporate personal religious or spiritual meanings. Courtney Bender's study Heaven's Kitchen (Bender 2003) gives an example of the ways in which cooking and care provide avenues for people to assign personal meaning to everyday practices. Similarly, Ammerman's study participants spoke about food and eating in relation to frugality, inequalities, eating together, and caring for the earth; some referred to disciplined eating as a spiritual practice (Ammerman 2014, pp. 232-37, 254). In Beaman's (Beaman 2017a) scrutiny of accepting religious differences in everyday life, some ordinary moments and encounters over a meal turned out to be significant. All in all, these studies hint that everyday ethics, food consumption, and lived (non)religion share a common basis.

In his effort to seek a way out of modernist tendencies to cognitively define religion in terms of beliefs and believing, Harvey goes as far as to suggest that "[p]erhaps religion (as a locus of scholarly 
attention) ought to be defined not as believing but as eating" (Harvey 2015, p. 32). In other words, the study of food not only tells us about religions; it helps us to understand religion. So far, research on religion, food and eating has mainly concentrated on specific foodways or specific religious groups and communities (Zeller 2015, p. 12). The collection of articles in the book Religion, food and eating in North America (Zeller et al. 2014) provides a timely example of the multiple ways in which these issues are connected and studied. In this article, I propose a slightly different approach: a shift from how and what certain religious groups or individuals eat to how eating constitutes and reflects the ethical worlds of secular societies and people who may or may not be religious.

In the next section, I present three selected insights into food consumption in contemporary society. None of them are explicitly related to religion. However, I suggest that they still (or hence) might assist us in understanding lived (non)religion. I have selected studies that operate on different levels of analysis. These include research into the ways in which individuals negotiate ethical food consumption, an analysis of contemporary public and scientific discourses of food and health, and research on societal practices in which surplus food is utilized for eating purposes. Importantly, all of the selected viewpoints provide insights into the responses towards the abundance of food in contemporary affluent societies.

\section{Responses to the Abundance of Food in Nonreligious Contexts}

\subsection{Negotiating Ethical Consumption in Everyday Life}

To begin with, we live in a world in which individual people are constantly invited to exhibit their identity, personality and values through their food choices (Johnston and Baumann 2015). In the wake of the processes of democratization, individualization, and a cultural shift that emphasizes subjective experiences, ordinary people, and their individual views and practices have been given pivotal positions, both as sources of social and ecological problems and as drivers of societal and environmental change. Food waste, for example, is generated in all phases of the food supply chain, but the largest quantities occur at the household level. It has been stated that it is indeed consumer aspirations and desires and the "consumptive environment" in which we live that keeps the unsustainable food system going (cf. Caraher and Furey 2017, p. 3). Given this centrality of food consumption in the everyday lives of individuals, a good way to begin a study of lived (non)religion could be to explore how ordinary people negotiate food consumption in relation to ethical questions.

When justifying certain food consumption practices, authenticity seems to play a key role in both high-status and ordinary food consumption. For example, Johnston and Baumann (2007) have analysed cuisine as a cultural realm that allows individuals to engage in displays of status. As regards high-status culinary consumption, authenticity and exoticism were emphasized in cultural selection as ways in which individuals could negotiate ideological tension between democracy and distinction. Grauel (2016), in turn, has studied how people present themselves as moral persons with regards to responsible consumption. He found that people often struggle with their consistency to engage in "good" consumption. The study paid attention to how the participants legitimize behaviour that is not in line with the ideals of ethical consumption.

According to Grauel's study participants, "good" food comes from known origin, is homemade or made without excess processing, and should be eaten consciously and healthily. The interviewees emphasized self-control and a healthy diet and a need to withdraw from food consumption that may cause harm to other people, animals, or the environment. Further, they considered frugality a virtue and gave credit for restricting oneself to what is necessary and rejecting what is excessive (Grauel 2016, p. 858). Importantly, even though the participants considered taking responsibility as a consumer important, they also problematized their ability to act according to these principles in practice. When their behaviour did not meet the ideals of being responsible, the interviewees justified this discrepancy by referring to personal taste or to external circumstances (Grauel 2016, pp. 860, 862). According to Grauel (2016, p. 862), "[p]ersonal taste seems to be the common sense that consumers can 
rely on in interactive communication with others, since it does not run the risk of offending others". In contrast to authentic consumption, ethical food consumption was labelled rigid and ideological. In this way, being authentic was attributed a moral quality, but without predetermining its moral content. In the study, submitting to the desires of the inner self served as a morally legitimate and socially constructed and accepted way to restrict moral responsibility in food consumption.

Living and dealing with domestic food surplus provides a further illustrative example. In his study of the ways in which food transforms into waste as a consequence of socially and materially organized domestic practices, Evans (2012) explores the mismatch between food provision and ordinary life or "the ways in which lives are lived" (Evans 2012, p. 45). In his research, the households studied routinely acquired more food than they were able to utilize, and most of this surplus ended up as food waste. At the same time, all the households under study shared the idea that good food cannot be thrown away. Wasting food caused negative emotions, such as worry and guilt. Consequently, even though most surplus food ended up uneaten, food was hardly ever thrown away immediately. Instead, the studied households engaged in careful procedures of retaining food items before they were put in the bin. According to Evans (2012, p. 46), "there is nothing careless or carefree about the acts of binning"; rather, even if the final outcome did not meet ethical ideals, the procedures of everyday life by which food was eventually wasted involved much concern and care. In individual food practices, the ideal of moderation is accompanied by careful acts of justifying and taking care of food surplus.

\subsection{Governing the Body in Public Health Discourse}

Further, in addition to individual experiences, the appearance of nonreligion as a significant sociological category leads researchers to think about the ideological and cultural forces that work as frameworks for ethical living in contemporary societies, in which traditional religious authorities lose caste as providers of order and meaning. One point of reference for such a research approach to religion could be the public discourse on food consumption. Food consumption is not only about subjective preferences or individual practice. Instead, the need for individuals to act or portray themselves as responsible consumers arises from wider societal frameworks in which food consumption is moralized. For example, in their reflection on moralities in food and health research, Askegaard et al. (2014) note that food has become one of the most significant lifestyle and life quality generators and markers. At the same time, public and scientific interest in the relationship between eating habits and public health is growing, placing questions regarding the moralization of food beyond individuals into the realm of public concern. These concerns, in turn, feed back to the level of the individual via an increasing supply of techniques and practices that aim to improve the health condition and physical appearance of the body.

Studying public and scientific discourses provides a window into understanding the ideological tenets of contemporary society. According to Askegaard et al., in contemporary public and health discourses, the moralization of food centres on health. They argue that

"contemporary societies are all to some degree permeated by the contemporary ideology of healthism (Crawford 1980) and are therefore subject to the collective and individual exercise of the imperative of health (Lupton 1995). This imperative of health, with its strategies of governance and its health technologies, is what creates the backdrop for the highly discursive and political presence of health in public and private lives. And it is this imperative that ultimately legitimises the inherent moralities in consumer behaviour and consumer research that we have tried to unpack". (Askegaard et al. 2014, p. 1820)

In an era of authenticity, subjective turn and therapeutic understanding of the self, scientific health discourse serves as a moral authority and an ethical point of reference that is outside the individual. Thus, it has the power to legitimate, produce and reproduce the moral imperatives, beliefs, and practices that govern both the public concern and private, embodied lives. 
In their study, Askegaard et al. (Askegaard et al. 2014, p. 1804) offer a typology of four moralities that direct contemporary discourses of food and health. These include the classification of food items as 'good' and 'bad', the management and stigmatization of body size, the resentment of the actions of market agents, and the idealization of moderation and self-control. From these four types of moral discourses, those that focus on body size and self-control are particularly relevant with regard to responding to abundance. According to Askegaard et al. (Askegaard et al. 2014, p. 1807), the dubious connotations still attached to indulgence are the legacy of the mind-body dualism and the Christian condemnation of gluttony as a deadly sin. Thus, the ethics of restrain are seen to have long theological and historical roots. Askegaard et al. (Askegaard et al. 2014, p. 1809) summarize the general outlook of food and health research by stating that "the individual has the moral obligation to resist (vs. give in to) immediate, short-term, concrete impulses in favour of abstract, long-term goals".

In its most visible form, achieving long-term health goals are measured by body size:

"Not only is overweight treated as an immediate sign of poor health, it is also considered to be the result of an individual's poor choices. As Kristensen and colleagues (2011, p. 197) point out, eating has become a notable site of individual responsibility: 'If you can do something about your consuming lifestyle and the alleged risks that follow from it, you should'. Together with perceptions of body size, this assumption of individual responsibility creates an impression that overweight individuals are solely responsible for their 'deteriorating' body, and hence that they are unwilling and unmotivated to exert self-control". (Askegaard et al. 2014, p. 1812)

In his analysis of "the governmentality of girth", Coveney (2006) makes similar notions. He notes that concern about excess body weight is not a new phenomenon. However, the scale at which concern over body size has become a dominating public health priority is unprecedented. According to Coveney (2006, p. 154), the utter physicality and visibility of fatness arouses reprehension, as it implies a neglect of the moral responsibilities of health. Moderation in the face of excessive food consumption and self-control in overcoming excessive body size are virtues, being cultivated by current public discussions and reproduced in food and health research.

\subsection{Institutional Practices of Living and Dealing (with) Surplus}

As noted at the beginning of this article, the origin of the contemporary challenges facing the sociology of religion has been traced to the paradigm that considers religion as a set of beliefs that fall within the realm of the private, transcendent, or inessential (Vasquez 2013; Harvey 2014). Overcoming this fallacy requires refocusing research on collective action and institutionalized, societal practices. Food consumption provides the means for such scrutiny, as it involves moral facets that span beyond individual choices and public discourses to the level of institutional practices. Thus, a further target for the study of lived (non)religion could be the institutional practices through which we approach living with an abundance of food at a societal level.

It is evident that the contemporary global food system routinely produces more food than we can consume (Katajajuuri et al. 2014). At the same time, although social stratification is nowhere more apparent than in foodways (Caplan 1994), in affluent societies, even the poorest consume unsustainably (Hirvilammi et al. 2014). In his study of corporate charity and the right to food, Riches (2018) points out two pivotal food-related challenges facing today's affluent societies. First, the global food waste crisis has prompted an imperative for governments, global institutions, and food markets to pursue goals that would ensure a more sustainable food system and less food waste. Second, and at the same time, food poverty, food insecurity, and even hunger still affect the lives of millions of people, even in the wealthiest countries in the world, an issue that calls for urgent government action.

One social praxis that has been invented to deal with the two concomitant, yet reverse issues of food insecurity and food waste is charitable food assistance, that is, a system and a mode of action in which food corporations, retailers, and religious and nongovernmental organizations join forces to 
redistribute surplus food to people that are afflicted by poverty and food insecurity. The food assistance system, which brings together food-surplus and food-insecure people, has often been portrayed as a simple, effective, and welcomed social innovation. It represents a deep concern for both the poor and the environment.

As a system that relies on food surplus, food aid is based on affluence and profusion: a food system that routinely produces more food than is possible to consume in primary food markets is a precondition for food aid. In other words, in the context of affluent societies, even the poorest cannot escape excess and waste. The paradox within the food assistance system is that it actually relies on the ongoing production of food surplus and on the premise that poor people exist who are in need of food (Salonen 2018; Riches 2018). Instead of fighting food surplus and poverty, the system requires excess food to feed the poor, and poor individuals and households to consume the surplus. In my previous work (Salonen 2018, p. 4) I have described the ambivalent moral character of food charity by stating that

"while surplus food is in principle morally reprehensible, it can be made more acceptable and easy to deal with by turning it into utility of charitable assistance. In progress, food assistance becomes an excess rescaling strategy and a means for normalizing food poverty and food surplus. As waste-based food assistance providers, many religious communities become middlemen in the processes of rescaling and decriminalizing excess and turning the vice of waste into a virtue".

Food charity is a strategy for rescaling excess, a societal practice that enables living with an abundance of food and excessive social problems, such as first world poverty. This particular way of dealing with food excess is interesting for the discussion about (non)religion as it represents a societal system that is proliferating in secularized societies and mostly discussed in terms of social policy or food security, yet often carried out in practice by religious organizations (see e.g., Lambie-Mumford and Jarvis 2012; Lambie-Mumford 2013; Noordegraaf 2010; Poppendieck 1999; Sack 2000; Tarasuk et al. 2014). By participating in food aid provision, religious communities become involved in societal practices in which the proper use of food surplus is negotiated and determined. In the institutional praxis of food assistance, food scarcity and profusion shake hands in an ethically highly ambivalent landscape.

In my study of users' perspectives on food charity, I found that many of those people who use food assistance in Finland live in socially and financially difficult situations, and many have experienced long-term, accumulated deprivation, misfortune, and scarcity (Salonen 2016). Yet, in the food assistance venues, these people occasionally experience an abundance of food. In practice, this abundance sometimes creates rather absurd situations for these people. For example, when substantial amounts of white bread or products containing refined sugar are available at these venues, what should a person suffering from diabetes or celiac disease do? What if these venues offer a great deal of convenience food or large portions of food, but the food recipient does not have a kitchen, or even a home? The institutional system of waste-based food assistance creates for its users an ambivalent social position in which they are both excluded from and dependent on the prevailing practices of consumer culture. At the same time, it bolsters an ambivalent identity of a non-choosing consumer, a person who opts out from exercising consumer choice in order to be fed.

As a parallel example, another societal issue that springs from the problem of the abundance of food is the question of the morality and legality of freeganism. Freeganism is a type of food consumption that voluntarily utilizes food abandoned by primary food markets. One notable freegan practice is bin-diving, that is, gleaning food for eating from, for example, the bins of food retailers or restaurants. Freeganism carries an undertone of ethical and ecological concern, as it is based on the idea of salvaging edible food and thus reducing food waste. Interestingly, however, particularly in relation to the practice of bin-diving, in wider society, freeganism also raises moral and legal concerns. It is morally suspicious because it involves eating food items that are condemned as waste by other societal instances. Further, as it involves interfering in someone else's property, even though this 
property has been abandoned, it has been accused of being an illegal practice. As a consequence, various institutionalized procedures have emerged by which grocery stores, for example, aim to make their binned food inaccessible, unattractive, or even inedible (Lehtonen and Pyyhtinen 2015).

As opposed to (often glorified) charitable assistance, which also uses excess and surplus as a resource, freeganism is considered as a deviant response to the prevailing consumer society that is characterized by abundance. It reveals the pervasiveness of waste in our society and mode of life (Lehtonen and Pyyhtinen 2015). At the same time, it raises questions regarding the ownership of waste, and it thus brings to light the ambiguity of the societal and moral status of abundance. A question of individual ethical food practice transcends into a matter of jurisprudence (cf. Thomas 2010).

\section{Discussion}

The rise of nonreligion as a significant social phenomenon blurs the categories of the religious and the secular (Woodhead 2017, p. 249). It forces us to rethink both the object of our research and the contexts of our studies. In her article about sea turtle rescue and lived nonreligion, Beaman (2017b, p. 27) called on sociologists of religion

"to reimagine our research in ways that extend our focus from religious groups, to the interaction between religion and nonreligion and to the environment that supports us and with which we are intimately connected. By so doing we are better able to capture the ways in which religion is folded into everyday life. These crossroads of increased nonreligion intersecting with religion in the context of a necessary reconfiguration of our relationship to the natural world not only opens a space of uncertainty, but also a space of opportunity for social scientists".

In this article, I have tried to sketch a preliminary, suggestive answer to this call by presenting some insights from studies of food consumption that have the potential to educate us in this emerging field.

The examples above first suggest that studying the ethics of everyday food consumption could provoke further thoughts regarding the research of lived (non)religion, by showing how people navigate between outspoken commitments and lived practices, or between ethical ideals and indifference. As stated above, indifference to religion might be the most significant characteristic of contemporary nonreligion. However, this indifference does not mean ethical indifference or moral unconcern. People-whether religious or not—are today as interested as ever in the surrounding world and give meanings to everyday incidents and perceptions of the wider whole in a way that makes reference to good and bad, or to right and wrong. In the words of Andrew Sayer, "our relation to the world is not merely causal and interpretative, but one of concern" (Sayer 2011, p. 20). The participants of Evans' study rejected being indifferent to everyday foodstuffs; instead they invested in their actions with profound concern, even though the food was eventually wasted. On the other hand, when asked to reflect their foodways, the participants of Grauel's (Grauel 2016) study seemed to adhere to the ideals of responsible consumption, while their everyday practices were possibly toned by ethical indifference, or by taste and desire, rather than responsibility. However, as Johnston and Baumann (2007, p. 199) note, following Bourdieu (1993), in culinary consumption, even disinterestedness is a form of taking a stance. In traditional approaches to religion, people have the opportunity to opt out by ticking the "no religion" box. In the context of food consumption, withdrawal is not an option. The study of food consumption can thus teach the sociology of religion about people's everyday struggles of being both concerned and indifferent towards ethically laden matters in ordinary life, in both religious and nonreligious contexts.

Second, the above studies on public health discourse suggest that food consumption is a discursive realm on which health is given the role of a qualitative and quantitative measuring rod that determines how we ought to live. Studying food consumption can educate the sociology of religion in the legitimate sources of authority and discipline in the contemporary world. On the level of public discourse, contemporary lived (non)religion calls for living a virtuous life that is centred around embodied 
practices of moderation and self-control, with references to nutrition and health sciences rather than divine authorities. The discourses of food aim to respond to abundance both with regard to the governance of food consumption and in terms of moralizing excessive physical bodies. In Grummet's (Grummet 2014, p. 4) words "[d]ietary practices are increasingly prominent as secular spiritual disciplines, being an area of everyday life in which practitioners seek to recover order, meaning, and purpose without making any personal commitment to Christianity or any other institutional religion". In a similar vein, but with additional reference to the scientific knowledge regarding nutrition, Coveney (2006, p. xvi) states that

"nutrition functions for modern subjects [ . . ] ] as both scientific and spiritual [ ... ] discipline. In other words, its serves a dual function by providing a range of scientific knowledges about food and the body through which individuals can be 'objectified', and by providing them with rapports á soil, or 'spiritual' discipline. 'Spiritual' here does not necessarily equate with 'theological' but refers to the means by which individuals are required to construct themselves with a 'correct' concern for the 'proper' way of behaving in relation to eating".

These disciplines do not only have the ability to provide insights into the individual, privatized forms of contemporary lived (non)religion, but into the ways and means by which they are materialized, produced, and reproduced in various public institutions, including scientific discourses.

Third, at the level of institutional practices, studying food consumption can instruct the sociology of religion by making the point that both food consumption and religion are lived, everyday matters that go beyond individual meanings and experiences and collective moral discourses, to the things that we do and value as communities and societies. Wirzba (2013, p. 378) outlines the theological value of food by stating that it "nurtures by building a community of responsibility and care, a community in which life together is affirmed as good". In other words, communal and societal food practices reflect societies as caring communities and expose their ideals of living together. However, it is not necessarily only the good side of living together that is affirmed in food consumption. Neither food consumption or religion are only nice things; they can - and often do-also involve harm. The above examples of surplus food reuse suggest that, at the societal level, in an affluent society, everyday food consumption brings forth responses to abundance that blur the boundaries between the vice of gluttony and the virtue of charity, and between legitimate and illegitimate (or illegal) actions. At the same time, the institutional practices feed back to the individuals by providing or imposing identities on people who participate or are influenced by them.

In the above sections, I have concentrated on studies that operate on different levels of analysis. I have provided examples from individual, discursive and institutional perspectives to illustrate how the everyday ethics of food consumption could help researchers to understand the currents of lived religion and nonreligion in a way that evades the idea of religion as a certain set of practices or beliefs, or as a specific religious affiliation. The discussion has left outside many questions concerning gender and race, as well as regional and food access issues. However, I acknowledge that a lot could be learned from these perspectives, too. The questions of gender, ethnicity, and social class would deserve more room than is possible to provide within the limits of one article in a way that would do justice to them. However, I hope that this article prompts new research that takes these themes seriously into account. At the individual level, for example, women still often bear the greatest responsibility for obtaining, managing, and disposing of food in many households, and the pressures caused by public health discourses about the representations of ideal bodies are unevenly distributed between class, gender and race (see, e.g., Cairns and Johnston 2015). Moreover, even in societies that are characterized by affluence, the questions concerning food access and equal distribution of food remain important, begging to take into account various social and societal divides. 


\section{Conclusions}

In this article, I have tried to unveil some potential sites that can prove insightful, if we take seriously the idea that religion is about living a virtuous life (Ammerman 2014), and the suggestion that religion might better be defined as eating than believing (Harvey 2015). As an opening, I suggest that food and eating provide one interesting avenue for research that transcends the boundaries between belief and practice, dogma and ethics, and religion and nonreligion. Eating can be seen as a lens through which to explore lived (non)religion; first, because of its ability to reveal how we engage in promoting good, and second, because it also reveals how we live and deal with or ignore the fact that our everyday practices cause harm, suffering, and violence. In other words, studying the ethics of everyday food consumption at various societal levels can guide us in studying how people either justify their deeds in order to take care of themselves, despite the acts of harm, or restrict their actions in order to take care of the well-being of others, as both individuals and societies, in both discourses and actions.

I consider the ideas presented in this article as preliminary suggestions that merit much further theoretical reflection and empirical research. By way of conclusion, I wish to point out some limitations and make some critical remarks. To begin with, as regards the linkages between food consumption and (non)religion, I do not claim that food consumption and foodways are equal to religion, or that they constitute a new religion in any way. There are many similarities between food consumption and the traditional conceptualizations of religion, such as their relations to rituals, beliefs, and practices. However, despite these resemblances, it would be a grave simplification to state that religion either reduces to foodways or that foodways merely "reflect" or "symbolize" religion as a tangible, this-worldly representation of something intangible and transcendent. Instead, I confine myself to suggesting that food consumption can serve as a point of departure for sociological research to understand the currents of lived religion and nonreligion in a way that evades the idea of religion as certain set of practices or beliefs or as a certain religious affiliation, yet allowing the study of matters, such as practices, beliefs, meanings, and belonging, as well as distancing, withdrawal, and indifference.

In addition, understanding lived (non)religion as everyday ethics requires two ancillary notions. First, such an approach entails recognizing people as both moral and rational beings. This stance relates to the Aristotelian view of human beings as striving for excellence and well-being (cf. Lambek 2010, p. 2). Moral sentiments have a rational, referential aspect: people tend to justify what they think and do, and monitor or sense what they and other people do on a scale of right and wrong, or good and bad (Sayer 2004). However, acknowledging that people are inclined towards moral reasoning need not mean that people have coherent moral or normative ideas; these are in fact often inconsistent, disparate, carried in stories and rituals, and are mixed with various situational logics rather than dogmatic tenets (Sayer 2004; Ammerman 2014, p. 7).

Second, understanding lived (non)religion as everyday ethics requires perceiving ethical conduct as situational, socially produced and reproduced, and inherent in speech and action. To paraphrase Askegaard et al. (Askegaard et al. 2014, p. 1802), individuals and communities cannot escape moralising, just as they cannot escape communicating (or eating, I am tempted to add). I adhere to the idea of everyday ethics in a similar way to that of Michael Lambek and others, considering ethics as a part of the human condition, and "as relatively tacit, grounded in agreement rather than rule, in practice rather than knowledge or belief, and happening without calling undue attention to itself" (Lambek 2010, p. 2). These tacit ethics become explicit, for example, through breaches, problems, and issues in which the right thing to do is unknown or contested (like when research participants struggle to present themselves as responsible consumers), through attempts to rationalize or educate (as in the scientific discourses on food and health) and through movements of social or ethical renewal (such as the incongruent efforts of food charity to fight food waste and food poverty). Everyday ethics is embedded in what individuals, communities and societies do as they deal with questions of good and bad, right and wrong; and when they respond to the challenges posed by the world around them. In contemporary society, this includes a necessary response to abundance. Routine 
everyday life is filled with ethical perspective-taking. Much of this becomes explicit in the situational contexts that require us to explicate or reflect our ordinary routines and practices. Hence, there are many opportunities for research.

Finally, the scene for lived (non)religion needs to be set with caution. This is particularly because such a task bears the danger of entrenching the division between religion and nonreligion, whereas based on what can be learned from the lived religion research tradition, the focus ought rather to be on reimagining, if not dissolving, such fixed boundaries. Moreover, Harvey (2013, p. 65) notes that the modern formation of categories in terms of religion has been accompanied by efforts to define the nonreligious, an undertaking that can itself be considered part of promoting particular (Protestant Christian) religious ideals as universal models for conceptualizing religion and the religious. However, I maintain that when studying particular western Christianity-influenced contexts, the concept of nonreligion has explanatory power; first, because it seems to serve as a point of reference on which many people can base their self-proclaimed identity, and second, because it aids in avoiding the impasse that is sometimes witnessed in inclusive lived religion approaches that seem to impose the category of religious on almost everything between heaven and earth. When dealing with individuals, religion is only one part of identity, and when it comes to society, religious traditions and histories lurk inevitably behind much of seemingly secular culture. With brackets, the concept of lived (non)religion can blur the boundary between religion and nonreligion and help to acknowledge the fuzziness, in-betweenness, and indecision regarding these terms, hence helping to steer the research focus on this-worldly affairs and "the real world religion" (cf. Harvey 2013)—or nonreligion.

Funding: This work was supported by the Academy of Finland under the projects Cooperation in care (decision number 275599) at the University of Helsinki and (Im)moderation in everyday food consumption (decision number 316141) at the University of Tampere.

Conflicts of Interest: The authors declare no conflict of interest.

\section{References}

Abbott, Andrew. 2014. The problem of excess. Sociological Theory 32: 1-26. [CrossRef]

Ammerman, Nancy T. 2014. Sacred Stories, Spiritual Tribes. Finding Religion in Everyday Life. Oxford: Oxford University Press.

Ammerman, Nancy T. 2016. Lived religion as an emerging field: An assessment of its contours and frontiers. Nordic Journal of Religion and Society 29: 83-99. [CrossRef]

Askegaard, Søren, Nailya Ordabayeva, Pierre Chandon, Tracy Cheung, Zuzana Chytkova, Yann Cornil, Canan Corus, Julie A. Edell, Daniele Mathras, Astrid Franziska Junghans, and et al. 2014. Moralities in food and health research. Journal of Marketing and Management 30: 1800-32. [CrossRef]

Beaman, Lori G. 2017a. Deep Equality in an Era of Religious Diversity. Oxford: Oxford University Press.

Beaman, Lori G. 2017b. Living well together in a (non)religious future: Contributions from the sociology of religion. Sociology of Religion: A Quarterly Review 78: 9-32.

Beaman, Lori G., and Steven Tomlins, eds. 2015. Atheist Identities: Spaces and Social Contexts. New York: Springer.

Beckford, James. 1989. Religion and Advanced Industrial Society. Controversies in Sociology. London: Unwin Hyman.

Bender, Courtney. 2003. Heaven's Kitchen: Living Religion at God's Love We Deliver. Chicago: The University of Chicago Press.

Bourdieu, Pierre. 1993. The Field of Cultural Production. New York: Columbia University Press.

Cairns, Kate, and Josee Johnston. 2015. Food and Femininity. London, New Delhi, New York and Sydney: Bloomsbury.

Caplan, Pat. 1994. Feasts, Fasts, Famine: Food for Thought. Berg occasional papers in anthropology, no 2. Oxford: Berg Publishers.

Caraher, Martin, and Sinead Furey. 2017. Is it appropriate to use surplus food to feed people in hunger? Short-term Band-Aid to more deep-rooted problems of poverty. Food Research Collaboration Policy Brief.

Coveney, John. 2006. Food, Morals and Meaning. The Pleasure and Anxiety of Eating, 2nd ed. New York: Routledge.

Dallam, Marie W., Benjamin E. Zeller, Reid L. Neilson, Nora L. Rubeland, and Martha Finch. 2014. Introduction. In Religion, Food, and Eating in North America. Edited by Benjamin E. Zeller, Marie W. Dallam, Reid L. Neilson and Nora L. Rubel. New York: Columbia University Press, pp. xvii-xxxii. 
Dobbelaere, Karel. 2014. The Karel Dobbelaere lecture: From the study of religions to the study of meaning systems. Social Compass 61: 219-33. [CrossRef]

Evans, David. 2012. Beyond the throwaway society: Ordinary domestic practice and a sociological approach to household food waste. Sociology 46: 41-56. [CrossRef]

Grauel, Jonas. 2016. Being authentic or being responsible? Food consumption, morality and the presentation of self. Journal of Consumer Culture 16: 852-69. [CrossRef]

Grummet, David. 2014. Dynamics of Christian dietary abstinence. In Religion, Food, and Eating in North America. Edited by Benjamin E. Zeller, Marie W. Dallam, Reid L. Neilson and Nora L. Rubel. New York: Columbia University Press, pp. 3-22.

Harvey, Graham. 2013. Food, Sex and Strangers. Understanding Religion as Everyday Life. Durham: Acumen.

Harvey, Graham. 2014. Elsewhere: Seeking alternatives to European understandings of "religion". Diskus: The Journal of the British Association for the Study of Religions (BASR) 16: 57-68. [CrossRef]

Harvey, Graham. 2015. Religion and Food, Religions as Foodways. REVER 15: 80-92. [CrossRef]

Hirvilammi, Tuuli, Senja Laakso, and Michael Lettenmeier. 2014. Kohtuuden Rajat? Yksin Asuvien Perusturvan Saajien Elintaso Ja Materiaalijalanjälki. [Within the limits of sufficiency? The standard of living and material footprint of singles subsisting on basic social security.] Sosiaali- ja terveysturvan tutkimuksia 132. Helsinki: Kelan Tutkimusosasto.

Hitlin, Steven, and Stephen Vaisey. 2013. The new sociology of morality. Annual Review of Sociology 29: 51-68. [CrossRef]

Honneth, Axel. 2010. Dissolutions of the social: On the social theory of Luc Boltanski and Laurent Thévenot. Constellations 17: 376-89. [CrossRef]

Johnston, Josée, and Shyon Baumann. 2007. Democracy versus distinction: A Study of omnivorousness in gourmet food writing. American Journal of Sociology 113: 165-204. [CrossRef]

Johnston, Josée, and Shyon Baumann. 2015. Foodies: Democracy and Distinction in the Gourmet Foodscape, 2nd ed. New York: Routledge.

Katajajuuri, Juha-Matti, Kirsi Silvennoinen, Hanna Hartikainen, Lotta Heikkilä, and Anu Reinikainen. 2014. Food waste in the Finnish food chain. Journal on Cleaner Production 73: 322-29. [CrossRef]

Lambek, Michael, ed. 2010. Ordinary Ethics. Anthropology, Language, and Action. New York: Fordham University Press.

Lambie-Mumford, Hannah. 2013. 'Every town should have one': Emergency food banking in the UK. Journal of Social Policy 42: 73-89. [CrossRef]

Lambie-Mumford, Hannah, and David Jarvis. 2012. The role of faith-based organisations in the Big Society: Opportunities and challenges. Policy Studies 33: 249-262. [CrossRef]

Lehtonen, Turo-Kimmo, and Olli Pyyhtinen. 2015. Roskisdyykkauksen objektit ja elämänmuodon rajat. [The objects of dumpster diving and the limits of our form of life]. Niin and Näin 85: 32-37.

Lorenz, Stephan. 2015. Having no choice: Social exclusion in the affluent society. Journal of Exclusion Studies 5: 1-17. [CrossRef]

McGuire, Meredith B. 2008. Lived Religion: Faith and Practice in Everyday Life. Oxford and New York: Oxford University Press.

Miller, William Ian. 1997. Gluttony. Representations 60: 92-112. [CrossRef]

Noordegraaf, Herman. 2010. Aid under protest? Churches in the Netherlands and material aid to the poor. Diaconia 1: 47-61. [CrossRef]

Orsi, Robert A. 2005. Between Heaven and Earth: The Religious Worlds People Make and the Scholars Who Study Them. Princeton: Princeton University Press.

Poppendieck, Janet. 1999. Sweet Charity? Emergency Food and the End of Entitlement. New York: Penguin Books.

Riches, Graham. 2018. Food Bank Nations: Poverty, Corporate Charity and the Right to Food. Routledge Studies in Food, Society and the Environment. London and New York: Routledge.

Sack, Daniel. 2000. Whitebread Protestants. Food and Religion in American Culture. New York: St. Martin's Press.

Salonen, Anna Sofia. 2018. Religion, poverty, and abundance. Palgrave Communications 4: 1-5. [CrossRef]

Salonen, Anna Sofia. 2016. Food for the Soul or the Soul for food: Users' Perspectives on Religiously Affiliated Food Charity in a Finnish City. Doctoral dissertation, University of Helsinki, Helsinki, Finland.

Sayer, Andrew. 2004. Restoring the Moral Dimension: Acknowledging Lay Normativity. On-line papers. Lancaster: Department of Sociology, Lancaster University, pp. 1-21. 
Sayer, Andrew. 2011. Why Things Matter to People: Social Science, Values and Ethical Life. Cambridge: Cambridge University Press.

Simmel, Georg. 1997. Sociology of the Meal. In Simmel on Culture: Selected Writings. Theory, Culture E Society. London: Sage.

Spickard, James V. 2017. Alternative Sociologies of Religion through Non-Western Eyes. New York: New York University Press.

Tarasuk, Valerie, Naomi Dachner, Anne-Marie Hamelin, Aleck Ostry, Patricia Williams, Elietha Bosckei, Blake Poland, and Kim Raine. 2014. A survey of food bank operations in five Canadian cities. BMC Public Health 14: 1-11. [CrossRef] [PubMed]

Thomas, Sean. 2010. Do freegans commit theft? Legal Studies 30: 98-125. [CrossRef]

Vasquez, Manuel. 2013. Grappling with the legacy of modernity: Implications for the sociology of religion. In Religion on the Edge: De-Centering and Re-Centering the Sociology of Religion. Edited by Courtney Bender, Wendy Cadge, Peggy Levitt and David Smilde. New York: Oxford University Press, pp. 23-42.

Wirzba, Norman. 2013. Food for theologians. Interpretation: A Journal of Bible and Theology 67: 374-82. [CrossRef]

Woodhead, Linda. 2017. The Rise of "No Religion": Towards an Explanation. Sociology of Religion: A Quarterly Review 78: 247-62. [CrossRef]

Zeller, Benjamin. 2014. Quasi-religious American foodways. The cases of vegetarianism and locavorism. In Religion, Food, and Eating in North America. Edited by Benjamin E. Zeller, Marie W. Dallam, Reid L. Neilson and Nora L. Rubel. New York: Columbia University Press, pp. 295-312.

Zeller, Benjamin. 2015. Totem and taboo in the grocery store. Quasi-religious foodways in North America. Religion and Food. Scripta Instituti Donneriani Aboensis 26: 11-31. [CrossRef]

Zeller, Benjamin E., Marie W. Dallam, Reid L. Neilson, Nora L. Rubeland, and Martha Finch, eds. 2014. Religion, Food, and Eating in North America. New York: Columbia University Press.

(C) 2018 by the author. Licensee MDPI, Basel, Switzerland. This article is an open access article distributed under the terms and conditions of the Creative Commons Attribution (CC BY) license (http:/ / creativecommons.org/licenses/by/4.0/). 